\section{PPPL-24i7}

UC20-F

TETR PLASMA REOIMES
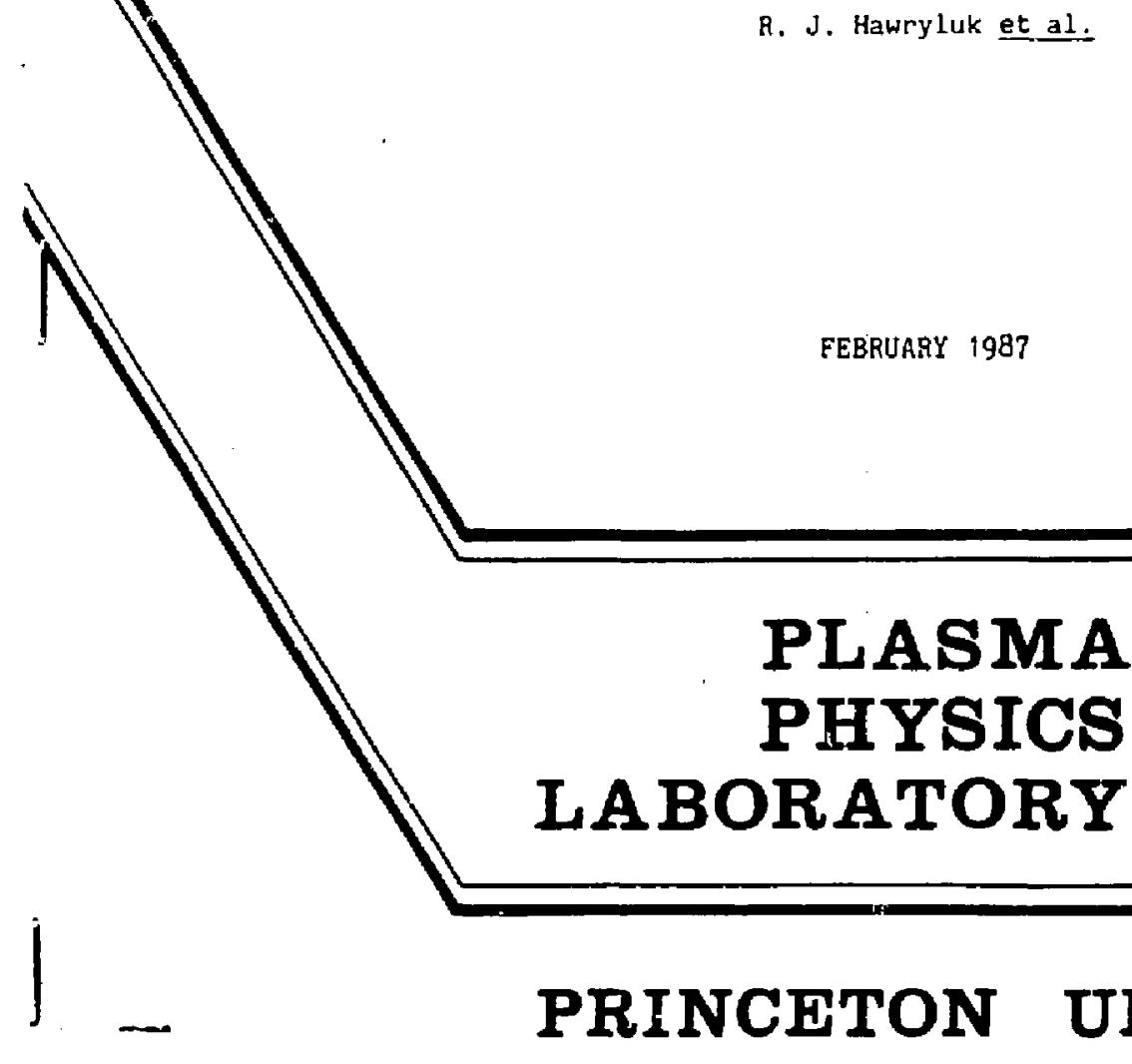

LABORATORY

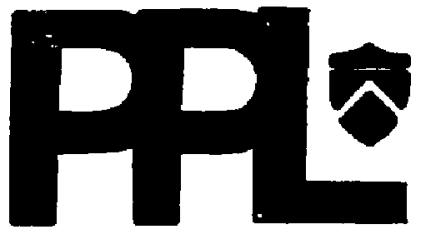

PRINCETON UNIVERSITY

PRINCETON, NEW JERSEY

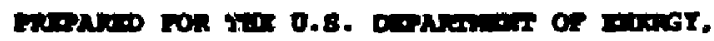

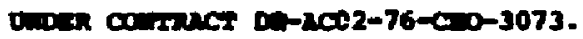


R.J. Hawryluk, U. Arunasalam, M.G. Bell, M. Bitter, W.R. Blanchard, N.L. Bręz, K. Budny, C.E. Bush*, J.D. Callen*, S.A. Cohen, S.X. Combs", S.L. Pavis, D.L. Dimpck, H.F. Dylla, P.C. Efthimion, L.C. Emerson", A.C. England", H.P. Eubank,

R.J. Fonck, E. Fredrickson, H.P. Furth, G. Gammel, R.J. Goldston, B. Grek, L.R. Grisham, G. Hamett, W.W. Hejidbrink ${ }^{*{ }^{*}}$,

H.W. Hendelt, K.W. Hill, E. Hinnoy, S. Hirae, R.A. Hulse,

H. Hsuan, K.P. Jaehri ig, D. Jasshy, D.W. Johnson, L.C. Johnson,

R. Kaita, R. Kamperschroer, S.M. Kaye, S.J. Kilpatrick,

R.J. Knize, H. Kugel, P.H. LaMarche, B. LeBlanc, R. Little,

C.H. Ma , D.M. Manos, D.K. Mansfield, M.P. MeCarthy, R.T. McCann,

D.C. McCune, K. McGuire, D.H. McfNelll, D.M. Meade, S.S. Medley,

D.R. Mikkelsen, S.L. Milara, W. Morristt, $f_{s}$ Mueller,

V. Mukhovatov ${ }^{\dagger t}$, E.B. Nieschmidt 5 , J. O'Rourke $\$$, D.K. Owens,

H. Park, N. Pomphrey, B. Prichard, A.T. Ramsey, M.H. Redi,

A.L. Roquemore, P.H. Rutherford, N.R. Sauthor, G. Schilling,

J. Schivell, G.L. Schmidt, S.D. Scott, S. Sesnic, J.C. Sinnis, E.J, Stauffer\$\$, B.C. Stratton, G.D. Tait, G. Tzylor,

J.R. Timberlake, H.H. Towner $r^{\prime}$ M. Ulrickson, V. Vershkov ${ }^{t}+t$, S. von Goeler, F. Wagner", R. Wieland, J.B. Hilgen",

M. Williams, K.L. Wong, S. Yoshikawa, R, Yoshino" " K.K. Young, M.C. Zarnstorff, V.S. Zaveriaev ttt, and S.J.'Zweben

Plasma Physics Laboratory, Princeton University P.0. Box 451, Princeton, NJ 08544

\section{* Permanent address: \\ * Permanent address: \\ Permanent address: \\ tPermanent address: \\ t†Permanent address: \\ tt Permanent address:}

$\$$ Permanent address:
$\$$ Permanent address:
$\$ 5$ Permanent address:
Permanent address:

* Permanent adoress:

\author{
Oak Ridge National Lab., Oak Ridge, TN \\ University of Wisconsin, Madison, WI \\ GA Technologies, San Diego, CA \\ RCA David Sarnoff Res. Ctr., Princeton, NJ \\ Balliol College, University of Oxford, UK \\ Kurchatov Institute of Atomic Energy, \\ Moscow, USSR \\ EG\&G, ídaho \\ JET Joint Undertaking, Abingdon, UK \\ University of Maryland, College Park, MD \\ Max Planck Institut fur Plasmaphysik, \\ Garching, FRG \\ Japan Atomic Res. Inst., Naka-machi, Japan
}

\section{DISCLAIMER}

This report was prepared as an account of work sponsored by an agency of the United States Government. Neither the United Seates Government nor any agency theseof, nor any of their employecs, makes any waranty, evpress or impliet, or assumes any legal liability or seiponsibility for the accuracy, completeness, or usefulness of any information, apparatus, prodict, or process disclosed, or represents that its use would not infringe privately owned rights. Reference herein to any specific commercial product, process, or service by trade name, trademark, manufacturer, or otherwise does not necessarily constitute or imply its endorsement, recommendation, of Javoring by the United Slates Government or any agency thereof The views and opinions of authors expressed herein do not necessarily state or rellect those of the United States Government or any agency thereof. 


\title{
TFTR PLASMA REGIMES
}

\begin{abstract}
Significant extensions in the TFTR plasma operating regimes have been achieved with additional heating-system capability, irstallation of a multishot pellet injector, and the development of an enhanced confinement regine. In ohmisally heated pelletfueled discharges characterized by highly peaked density profiles, enhancements in $t_{E}$ have resulted in $\pi_{e}(0) \tau_{E}(a)$-values of $1.5 \mathrm{x}$ $10^{20} \mathrm{~m}^{-3} \mathrm{~s}$. In neutral-beam-h, ated discharges, an operating regime has been developed in which substantial improvements in energy confinement time and neutron source strength are observed. Ign temperatures of $\sim 20 \mathrm{keV}$ and $n_{e}(0) \tau_{g}(a) T_{j}(0)$-values of $2 \times 10^{20}$ $\mathrm{m}^{-3} \mathrm{~s}$ kel have been achieved. This enhanced confinement regime is characterized by high values of $\beta_{\text {and }}$ low values of collisionality. The observed surface voltage, which is negative during beam injection, is compared with models including beamdriven and bootstrap currents.
\end{abstract}

\section{Introduction}

The goals of the TFTR project are (1) to study reactor-grade piasmas with temperatures of order $10 \mathrm{keV}$ and densities of order $10^{20} \mathrm{~m}^{-3}$, and (2) to achieve approximate breakeven between the power input to and the fusion output from the plasma $(Q-1)$. During the past year, high-power neutral-beam-heating experiments and ohmicheating experiments utilizing a deuterium pellet injector have significantly. extended the operating regimes of TFTR, as measured by the $n_{e}(0) \tau_{F}(a) T_{i}(0)$ product and the $Q$-value achieved in neutral-beam-heated discharges.

This paper gives a brief description of the TETR device status and the operating regimes in gas-fueled and pellet-fueled ohmic discharges. A more extensive discussion of the pelletfueled discharges is given by Schmidt et al. [1]. Results from neutrai-beam-heating experiments in the standard regime are also summarized briefly. A general description is given of the operating characteristics of discharges in the enhanced confinement regime; further information is contained in the papers by Goldston et al. [2], McGuire et al. [3], and Hill et al. [4].

\section{Machine Status}

An initial series of experiments with two (co-injecting) neutral beamlines was completed in Aprit 1985, during which TETR reached its original machine design specifications for plasma current and toroidal field ( $I_{p}=2.5 \mathrm{MA}$ and $\mathrm{E}_{\mathrm{T}}=5.2 \mathrm{~T}$ ) [5]. Subsequently, two additional beamlines were installed; three beamines are now aimed tangentially in the direction of the plasma current (co-injection), and one opposite (counterinjection). During the recent experiments, the maximum injected power was $20 \mathrm{MW}$ with a full energy component, of - $10 \mathrm{Mk}$. The maximum beam voltage was $110 \mathrm{kV}$, and the maximum puise duration 
$1.0 \mathrm{~s}$. Most of the experiments were conducted wich $0.5 \mathrm{~s}$ pulse lengths and an average beam voltage of $\sim 95 \mathrm{keV}$. Deuterium injection was used in all of the experiments discussed here. During the last beamline installation, a large-area axisymetric inner wall limiter was also installed. This limiter is composed of water-cooled Inconel plates covered with graphite tiles. The toroidal iriner wall limiter and moveable limiter define the present maximum plasma dimensions as $R=2.48 \mathrm{~m}$ and $a=0.82 \mathrm{~m}$.

\section{II. Ohmically Heated Discharg̉es}

Initial ohmic experiments reported in 1984 [6] at modest toroidal fields ( $\leq 2, \mathrm{~T})$, plasma currents $(\leq 1.4 \mathrm{MA})$, and densities $\left(\bar{n}_{\mathrm{e}}<3 \times 10^{19} \mathrm{~m}^{-3}\right)$ demonstrated that the global energy confinement time, ${ }^{\top}{ }_{E}$, scales consistent with $\bar{n}_{e} q R^{2} a$, reaching a maximum value of ${ }^{T} E-0.3 \mathrm{~s}$. Subsequent experiments utilizing both gas- and peliet-fueled discharges have concentrated on exploring the applicability of this scaling law over a wider operating range in density, toroidal field, and plasma current.

The analysis of the energy confinement time has relied principally upon a time-independent kinetic analysis code, SNAP, [5] and has been supplemented by magnetic measurements [7]. Eigure 1 is a summary of the onmic-heating studies for full bore plasmas. In gas-fueled deuterium discharges, the confinement time increases up to $0,44 \mathrm{~s}$, in reasonable agreement with $\mathrm{n}_{\mathrm{e}} \mathrm{q}_{\mathrm{a}}$ scaling for $\bar{n}_{\mathrm{e}} \leftrightharpoons 4.8 \times 10^{19} \mathrm{~m}^{-3}$. At higher densities, saturation is found to occur for both helium-gas- anj deuterium-pellet-fueled discharges. In the high density regime, the confinement time is observed to be a weak function of plasma current.

In addition to increasing the line-averaged density, pellet injection produces highly peaked density profiles. A lineaveraged density of $1.4 \times 10^{20} \mathrm{~m}^{-3}$ has been achieved $200 \mathrm{~ms}$ after the injection of five $2.7 \mathrm{~mm}$ pellets in experiments conducted on the inner graphite limiter. This corresponds to a Murakami

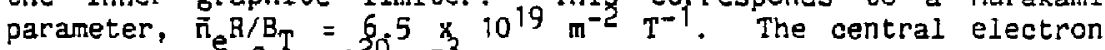
density was $2.8 \times 10^{20^{\circ}} \mathrm{m}^{-3}$ and central electron temperature was $1.4 \mathrm{kel}$ as measured by Thomsen scattering. This peaked density profile was achieved by operating with a reduced plasma minor radius of $0.7 \mathrm{~m}$ and a plasma current of $1.6 \mathrm{MA}$, in order to improve pellet penetration. The energy confinement time was $0.50 \mathrm{~s}$ according to kinetic and diamagnetic measurements corresponding to an $n_{e}(0) \tau_{E}=1.4 \times 10^{20} \mathrm{~m}^{-3} \mathrm{~s}$. The energy confinement time is - $20 \%$ greater than that achieved in gas-fueled discharges with the same values of $I_{p}, R$, and $a$, using either deuterium or helium as the working gas.

\section{Neutral-Beam-Heating Studies in the Standard Regime}

The variation of energy confinement time with injection power up to $\sim 15 \mathrm{MW}$ was studied systematically. These experiments were conducted in the large plasma configuration on the inner wall 
limiter with deuterium gas fueling, deuterium beams, $I_{0}=1.4$ and $2.2 \mathrm{MA}$, and $\mathrm{B}_{\mathrm{T}}=4.8 \mathrm{~T}[7]$. Figure 2 shows the variation in the total stored energy for tile 1.4 and 2.2 MA power scan with a constraint on the density at the end of injection. Kinetic and magnetic measurements (using the techniques described in Ref. 7) are in good agreement. The stored energy increases linearly with heating power; however, the rate of increase of stored energy, $\mathrm{dW} / \mathrm{de}$ heat, is appreciably less than the ohmic confinement time. The gross energy confinement time $\tau_{E}(a)$, defined as $H_{T O T} /\left(P_{T O T}-\right.$ $\mathrm{dW}_{\mathrm{TOT}} / \mathrm{dt}$ ), where $W_{\mathrm{TOT}}=W_{\mathrm{e}}+W_{\mathrm{i}}+w_{\mathrm{b}}$ and $\mathrm{P}_{\mathrm{TOT}}=\mathrm{P}_{\mathrm{OH}}+\mathrm{P}_{\mathrm{INJ}}$ for the data shown in Fig. 2 , can be fitted to a form $a+{ }_{B} / P_{T O T}$, where a is the "incremental" confinement time. In the plasma density range of $3.4<\bar{n}_{e}<4.3 \times 10^{19} \mathrm{~m}^{-3}$, a increases with plasma current from $61 \mathrm{~ms}$ to $94 \mathrm{~ms}$ as the current is increased from 1.4 to $2.2 \mathrm{MA}$. The energy confinement time is abserved to depend weakly upon density; however, a negative scaling of a with increased density is observed in the $1.4 \mathrm{MA}$ discharges. At low density, the enhancement in stored energy at high power occurs in the beam and thermal ions, since the electron stored energy decreases slowly with decreasing density. The high-power beam heating in this current and density range results are also in fair agreement with the Goldston L-mode model [8] for hydrogen injection into deuterium plasma. Power-law fits to the data shown in Fig. 2 indicate that $\mathrm{H}_{\text {TOT }} \propto \mathrm{P}_{\text {TOT }} .46 \mathrm{I}_{p} 0.91$ for $\mathrm{P}_{\text {TOT }}>4 \mathrm{MW}$ $[7]$.

\section{Niutral Beam Heating in the Enhanced-Confinement Regime}

Previous operation of TFTR at low I $(0.4-1.0 \mathrm{MA})$ and moderate beam power ( $P_{b} \& 6$ MW) using on $P_{y}$ co-injection [5] allowed access to a very low-density regime $\left(\tilde{n}_{\mathrm{e}} \sim 1 \times 10^{19} \mathrm{~m}^{-3}\right)$, characterized by high values of ion temperature $(\sim 9 k e V)$ and rapid toroidal rotation velocity (up to $\sim 7 \times 10^{5} \mathrm{~m} / \mathrm{s}$ ). Recent experiments in this regime conducted at higher power ( $s 20 \mathrm{MW}$ ), using both co- and counter-injection have demonstrated enhanced confinement relative to the predictions of $L$-mode scaling, along with central ion temperatures of $\sim 20 \mathrm{keV}$ at $\overrightarrow{\mathrm{n}}_{e} \sim 3 \times 10^{19} \mathrm{~m}^{-3}$ with a central $\mathrm{n}_{e}(0)-7 \times 10^{19} \mathrm{~m}^{-3}$ [9]. The achievement of this improved performance relative to the previous experiments is due to extensive degassing of the limiter and near-balanced injection $\left(P_{\text {ctr }}-P_{C O}\right)$.

A procedure that results in a low recycling rate as shown by decreases in the $D_{a}$ emission and edge neutral pressure is identified to be critical in giving rise to the enhanced confinement regime $[4,10]$. Both low-density deuterium and helium discharges have been used to degas the inner wall. These high power discharges (0.8-1.8 MA) were not fueled following breakdown. Helium discharges were more effective in reducing the iow-density limit and the decay time of the density following a diagnostic gas puff. The density decay time has been decreased from $>5 \mathrm{~s}$ to as low as $\approx 0.15 \mathrm{~s}$ after extensive degassing. The Low initial density of the target plasma and relatively high $Z$ eff - 6 is a consequence of the degassing procedure which effectivefy 
removes $D^{+}$from the target plasma. The large density rise during injection $\left[\bar{n}_{e}\right.$ (final) $/ \bar{n}_{e}$ (prior to injection) $\left.\leq 3-4\right]$ is accompanied by a decrease in $Z_{\text {eff }}$ to -3 at the end of injection.

Figure 3 shows a comparison of the temporal evolution of two discharges during neutral beam injection with different initial line-integral densities, different deuterium recycling rates due to different degassing histories, and comparable final lineintegral densities. In the discharge with the lower initial density, both tne neutron source strength and the stored energy increase throughout the $0.5 \mathrm{~s}$ neutral beam pulse. The global energy confinement time is also substantially longer. Discharges that exhibit continually rising stored energy and neutron source strength during the half-second beam-injection have been colloquially termed "supershots." Experiments conducted in the final days of the experimental run demonstrated continued increase in stored energy with $0.7 \mathrm{~s}$ duration beam pulses and that the stored energy approached equilibrium with $1.0 \mathrm{~s}$ duration pulses. At plasma currents up to $1 \mathrm{MA}$, values of $\beta_{p}=2.0$ from plasma diamagnetism have been measured. Maximum values of $B$ up to 2.2 have been achieved transiently. These high values of $g_{p}$ result in substantial outward shifts of the magnetic axis $\left(R_{p a p}-R_{g e o}\right) / a$ S 0.4 and distortions of the plasma shape. The vertical elongation, $\kappa$, decreases from 1.05 to $\leq 0.9$ in the most extreme cases. Eigure 4 shows a comparison of the electron temperature and density profiles measured near the end of the pulse for the discharges shown in Fig. 3. The discharge with the lower initial density (supershot) has a more peaked density profile, with a higher central density and a much broader electron temperature profile. Peak central electron temperatires of $\sim 6.5 \mathrm{keV}$ during injection have been obtained in supershots.

The central ion temperature is measured using several tyechniques. X-ray Doppler-broadening measurements have been carried out for $\mathrm{Ee} X X V$ and $\mathrm{Ni}$ XXVII $\mathrm{K}_{\alpha}$ lines using a horizontally viewing crystal spectrometer and three vertically viewing spectrometers. The horizontai channel is rendered ineffective due to neutron noise during supershots. In the analysis of the vertical detectors the large shift in magnetic axis needs to be taken into account. For the data shown in Fig. 5, the emitting region viewed by the vertical detector is $-0.2 \mathrm{~m}$ outside of the magnetic axis. Doppler-broadening measurements in the VUV have also been used to obtain central ion temperatures. The spectrometer has a horizontal radial view of the plasma. Onedimensional impurity transport simulations including chargeexchange recombination indicate that the mean radius of the emission profile for the lithium-like ions used is $-0.2 \mathrm{~m}$. The heating beans have permitted preliminary spectroscopic measurements utilizing carbon lines excited by charge-exchange recombination. Good agreenent between the various measurements is achieved.

Figure 5 shows the variation in central ion temperature for discharges in the standard neutral-beam-heating regime $\left(I_{p}=1.4\right.$ 
and $2.2 \mathrm{MA}$ ) and for both super and non-super low-current discharges $(0.6<I<1.1 \mathrm{MA})$. In the low-current discharges, considerable variablitity in the heating results is obtained, reflecting the occurrence of MHD activity, varfations in limiter history, and variations in the fraction of power in the codirection. Taking into account uncertainties in the measurements and the calculated differences between the impurity and hydrogenic ion temperatures which are $<2 \mathrm{keV}$, these results indicate central bulk ion temperatures of $-20 \mathrm{keV}$. The maximum value of the ion hezating efficiency parameter, $\bar{n}_{\mathrm{e}} \Delta \mathrm{T}_{\mathrm{i}} / \mathrm{P}_{\text {INJ }}$, is $-3.8 \times 10^{13} \mathrm{keV} \mathrm{\textrm {W } ^ { - 1 }}$ $\mathrm{m}^{-3}$. This is in comparisog with previous experiments [5] in which $\overline{\mathrm{n}}_{\mathrm{e}} \Delta \dot{\mathrm{T}}_{\mathrm{i}} / \mathrm{P}_{\text {INJ }}$ was $-1.5 \times 10^{13} \mathrm{keV} \mathrm{\textrm {w } ^ { - 1 }} \mathrm{a}^{-3}$.

Figure 6 shows the scaling of stored energy with power. An important characteristic of the enhanced confinement regime is the fraction of power in the co-direction, $\mathrm{P}_{\mathrm{CO}} / \mathrm{P}_{\text {INJ }}$. As shown in $E$ ig. 6 , at a given power the highest stored energy (and hence $\tau_{E}$ ) is achieved with nearly balanced injection $\left(F_{C_{0}} / P_{\text {INJ }} \sim 0.5\right)$ in discharges with degassed limiters. In Fig. 6 , the data set was constrained to eliminate discharges with very-large-amplitude continuous MHD activity [3]. With nearly balanced injection the stored energy increases linearly with heating power and the incremental confinement time is $0.15 \mathrm{~s}$, comparable to the lowdensity ohmic confinement time prior to injection. Furthermore, with near balanced infection the global confinement time is not observed to degrade with power: values up to $0.17 \mathrm{~s}$ are achieved with $12 \mathrm{WW}$ as shown in $\mathrm{Fig}$. 7 , and the confinement time is, up to 3 times the prediction of Goldston L-mode scaling [8]. With the present discribution of beam sources, at full power $\mathrm{P}_{C O} / \mathrm{P}_{\mathrm{INI}}$ is 0.7 which is not optimum, as indicated in Fig. 7. The highest power experiments were conducted at higher current $(1.0 \mathrm{MA})$ to minimize the effects of MHD activity.

The energy stored in the discharge appears to be limited by a maximum $B_{p}$ value of -2 . Further increases in power at a given current result in either disruptions or MHD activity degrading the stored energy [3]. At low toroidal field and modest $q_{a}(-4-5)$, the maximum stored energy is in fair agreement with the Troyon $B_{T}$ limit [ $\left.\mathrm{G}_{\mathrm{T}}^{\max } \times(2.2-2.5] \mu_{\mathrm{O}} \mathrm{I}_{\mathrm{g}} / \mathrm{aB}_{\mathrm{T}}\right][11]$. At high toroidal rield and $q_{a}$ the Troyon $B_{T}$ limit would permit $B_{p}$ values up to $\sim 3.5$.

At higher plasma rurrent $\left(I_{p}>1.1 \mathrm{MA}\right.$ ), the favorable characteristics of supershots have not been observed, and the difference in $\tau_{E}$ between balanced and co-only injection at $\mathrm{P}_{\mathrm{b}}=$ $10 \mathrm{MW}$ is less than 15\%. Supershot characteristics at higher current ( $1.3 \mathrm{MA}$ with $17 \mathrm{MH}$ of neutral beam power) can be achieved by ranping the current from 0.9 MA during the beam pulse, resulting in $q_{a} \approx 5$. Further extension of the operating regime may be possible with the longer-duration $(2.0 \mathrm{~s})$ and higher-fullenergy-species-mix beam sources $(80 \%$ power at full energy) that are currently being installed. Present current-ramp experiments are encouraging in that supershot characteristics are observed even when falrly large current-ramp rates up to $1 \mathrm{MA} / \mathrm{sec}$ are appiled. By talloring the beam power waveform and the current 
ramp, it may be possible to achieve supershots with mush higher currents, thus avoiding the a limits.

In discharges in which the plasma current is maintained constant by feedback control, the surface voltage is observed to decrease from the ohmic phase with increasing $B_{p}$ and co-injected power and is typically - $-0.2 \mathrm{~V}$ at che end of injection. Though the electron temperature increases and broadens and $Z_{\text {eff }}$ decreases, changes in conductivity alone cannot produce a negative voltage. The changes in plasma geometry coupled with changes in conductivity are also not large enough to account for the negative voltage, as determined by a one-and-one-half-dimensional magnetic field diffusion calculation. Monte Carlo beam calculations show that neoclassical beam-driven currents [12] contribute to the decrease in surface voltage, but still do not account for the magnitude. The calculations show that, due to the beam orbits, co-injection is more effective in driving current, particularly in outer regions of plasma, than counter-injection; thus even when the power is nearly balanced, a net beam-driven current effect on the surface voltage is calculated. By including the neoclassical bootstrap current predicted by Galeev and Sagdeev [13] and Bickerton et al. [14] as formulated by Hirshman and Sigmar [12], good agreement is obtained between the calculated and measur id surface voltage, as shown in Fig. 8. These calculations indicate that for this case approximately $350 \mathrm{kA}$ of bootstrap current is present, compared with $420 \mathrm{kA}$ of co-injected current and $-160 \mathrm{kA}$ of counter-injected current. In presently analyzed discharges, the maximum calculated bootstrap current is $440 \mathrm{kA}$ in a $900 \mathrm{kA}$ plasma with $370 \mathrm{kA}$ of calculated beam-driven current. While the driven currents do not exceed the total current, the calcuiated voltage is negative because the radial cistribution of the bootstrap current is broader than that of the ohmic current, exceeding the total current density in the outer region of the plasma.

Operation in the supershot regime has resulted in substantial increases in neutron source strength and equivalent $Q$. The maximum neutron source sirength of $1.2 \times 10^{16} \mathrm{n} / \mathrm{s}$ was achieved with $19.6 \mathrm{MW}$ of bear power with $\mathrm{P}_{C O} / \mathrm{P}_{I N \mathrm{~N}}=0.7$. The maximum $Q_{D D}$ of $8.7 \times 10^{-4}$ was achieved with $12.3 \mathrm{MW}$, when the power was more nearly balanced ( $\mathrm{P}_{\mathrm{CO}} / \mathrm{P}_{\mathrm{INJ}} \approx 0.5 \mathrm{G}$ ), corresponding to a source strength of $8.9 \times 10^{15} \mathrm{n} / \mathrm{s}$. In the supershot regime, SNAP and time-dependent (TRANSP) calculations of the neutren flux are in good agreement ( $\pm 25 \%$ ) with the measured flux. These calculations indicate that, for the discharge with the highest value of $Q_{D D}$, 172 of the flux is due to beam-beam reactions, 537 due to beam-target, and $-30 \%$ from the thermalized ions shortly before the end of the beam pulse. In order to estimate the $Q_{D T}$ which would be achieved with deuterium and tritium, it is necessary to assume a composition for the hydrogenic component of the target plasma. For the hypothetical condition of deuterium beam injection into a tritium plasma ( $w i t h$ the same value of 2 eff $=3.3)$, Q Q would be 0.23 , due to beam-target reactions. Because beam fueling is clearly very important, a more realistic case 
would be to consider injection using deuterium and tritium teams into a 50\%/50\% deuterium/tritium plasta. In this case, the resulting value of $Q_{0 T}$ would be $\approx 0.18$. A sigaificant improvement over these values can be expected from the new long pulse ion sources with better species mix, operation at $120 \mathrm{kV}$, and nearly balanced injection at full beam power, even without assuming higher injected power and improved plasma parameters.

\section{Sunmary}

During the past year, substantial progress has been made in expanding the operating range of TETR. Ohmically heated pellet.. fueled discharges have resulted in exceptional ceptral densities and $n_{e}(0) \tau_{E}(a) \quad T_{i}(0)$ vailies of $-2 \times 10^{20} \mathrm{~m}^{-3} \mathrm{~s} \mathrm{keV}$. Furthermore, in the saturated regime, the confinement time in pellet-fueled discharges is observed to be longer than that achieved in gas-fueled discharges. In these discharges, the density profile is very peaked $n_{e}(0) / \bar{n}_{e}-2$.

In neutral-beam-heated discharges an enhanced confinement regime has been found. This regime is characterized by peaked density profiles, broad electron temperature profiles, high ion temperacures $=20 \mathrm{keV}$, and high neutron source strengths. In this regime, $n_{g}(0) \tau_{E}(a) T_{i}(0)$-values of $\sim 2 \times 10^{20} \mathrm{~m}^{-3} \mathrm{~s} \mathrm{keV} \mathrm{have} \mathrm{also}$ been achieved. The operating regime is characterized by a low initial density and deuterium recycling prior to infection, which can only be achieved at low $I$ and after extensive Iimiter degassing. At high toroidal field ( $B_{T}=5.2 \mathrm{~T}$ ), this corresponds to relatively high values of $q_{a}$ (in the range of 7-8) and $\beta_{p}$ (up to 2). In reduced toroidal field experiments and in current ${ }^{\mathrm{p}}$ ramp experiments, supershots with $q_{a}-4-5$ have been obtained. Significantly improved performance is achieved with nearly balanced injection.

In the high temperature regime, the plasma collisionality is low and $B$ is high, so that both beam-driven currents and bootstrap currents are predicted to be important. Calculations including bootstrap current are in better accord with the experimental measurements than those including only the beamdriven currents. If these indications of the bootstrap current are verified by future experiments, the performance of tokamak reactors could be fundamentally enhanced.

\section{Acknowledgements}

We are grateful to D.J. Grove and J.R. Thompson for their advice and support, and to J. Strachan for his many contributions. This work was supported by US DOE Contract No. DEACO2-76CH03073. The ORNL participants were also supported by US DOE Contract No. DE-AC05-840R21400 with Martin Marietta Energy Systems, Inc. 


\section{REFERENCES}

[1] SCHMIDT, G., et al., Presented at the iltin Internationa] Conference on Plasma Physics and Controlled Nuclear Fusion Research, Paper No. A-III-4 IAEA (1986) Kyoto, Japan.

[2] GOLDS'ION, R.J., et al., Presented at the 11 th International Conference on Plasma Physics and Controlled Nuclear Fusion Research, Paper No. A-II-1 IAEA (1986) Kyoto, Japan.

[3] MCGUIRE, $K$., et al, Presented at the 19th International Conference on Plasma Physics and Controlled Nuclear Fusion Research, Paper No. A-VII-4 IAEA (1986) kyoto, Japan.

[4] HiLL, K., et al., Presented at the 11th International Conference on Plasma Physics and Controlled Nuclear Fusion Research, Paper No. A-IV-2 IAEA (1986) Kyoto, Japan.

[5] MURAKamI, M., et al., Plasma Phys. Controlled Eusion 28 (1986) 17 .

[6] EFTHIMION, P.C., et al., (Proc. Plasma Physics and Controlled Nuclear Fusion Research) IAEA, Vienna I (1985) 29.

[7] BELL, M.G., et al., Plasma Phys. Controlled Fusion 28 (1986) 1329.

[8] GOLDSTON, R.J. Plasma Phys. Controlled Fusion 26 (1984) 87.

[9j STRACHAN, J.T., et al., (1986) submitted for publication to Phys. Rev. Lett.

[10] DYLLA, H.F., et al., (1986) submitted for publication to Nucl. Fusion.

[11] TROYON, F., et al., Plasma Phys. Controlled Fusion 26 (1984) 209.

[12] HIRSHMAN, S.P., and SIGMAF, D.J., Nucl. Fusion 21 (1981) 1079.

[13] GALEEV A.A., and SAGDEEV R.Z., Zh. Eksp. Teor. Fiz. 5.3 (1967) 348 [Sov. Phys. - JETP 26 (1968) 233].

[14] BICKERTON, R.J., CONNER, J.H., and TAYLOR, J.B., Nat. Phys. Sci. $229(1971) \div 10$. 


\section{FIGURE CAPTIONS}

Fig. I Gross energy confinement versis $\bar{n}_{e} q_{a} R^{2}$ for ohmically heated discharges with and without pellet injendion. The i.6 MA discharges had reduced aperture, $a=0.7 \mathrm{~m}$ compared with the other full-size $0.8 \mathrm{~m}$ distharge:

Fig. 2 Variation of the stored energy for 1.4 ar $\{2.2$ MA power scans for a constrained density range and $s_{T}=4.8 T, R=$ $2.48 \mathrm{~m}$, and $a=0.82 \mathrm{~m}$. Magnetic measurements are compared witr: prediction of the Goldston L-mode model.

Eig. 3 Comparison of the evolution of line average density, neutron source strength, $\mathrm{H}_{\mathrm{a}}$ emission (which includes both $\mathrm{H}_{\mathrm{a}}$ and $\mathrm{D}_{\mathrm{a}}$ emission) and stored energy for two discharges. The solid curve corresponds to a supershot. $R=2.48 \mathrm{~m}, a=0.82 \mathrm{~m}_{2} P_{b}=12.5 \mathrm{wW}$, and $B_{\mathrm{T}}$ $=4.7 \mathrm{~T}$ in the supershot discharge whereas $\mathrm{F}_{\mathrm{b}}=11.4 \mathrm{MW}$ and $\mathrm{B}_{\mathrm{T}}=5.0 \mathrm{~T}$ in the non-super shot.

Fig. 4 Comparison of. Thomson scatuering measurements of the electron temperature and density prosiles at $4.45 \mathrm{~s}$ for the dischar'ges shown in Figure 3. The solid points are for the supershot discharge and the open circles are for the non-super shot.

Fig. 5 Ion temperature versus $P_{I N J} / \tilde{n}_{e}$. Closed symbuis are for $4.8<\mathrm{B}_{\mathrm{T}}<5.2 \mathrm{~T}, 0.8 \leq \mathrm{H}_{\mathrm{P}} \leq 7.0 \mathrm{MA}, \mathrm{R}=2.45 \mathrm{~m}$, and $\mathrm{a}=$ $0.80 \mathrm{~m}$ and open symbals are for the discharges shown in Fig. 2.

Eig. 6 Variation of stored energy with injected power for different values of iractional power in the co-direction for $4.7<B_{T}<5.2 \mathrm{~T}$ and $2.40<\mathrm{R}<2.48 \mathrm{~m}$ and $0.76<\mathrm{a}<$ $0.82 \mathrm{~m}$. Magnetic measurements are compared with the predistion of the L-mode model of Goldston.

Fig. 7 Variztion of global confinemenc cime with injected power for the data set is shown in Eig. 6. Magnetic measurements are compared with the prediction of the Lmode model of Goldston.

Fig. 8 Comparison of the measured surface voltage with the calculated surface voltage under different assumptions for the role of non-ohmically driven currents. The discharge parameters are $\mathrm{B}_{\mathrm{T}}=5.2 \mathrm{~T}, \mathrm{~B}=2.45 \mathrm{~m}$, and $\mathrm{a}=$ $0.8 \mathrm{~m}$. 


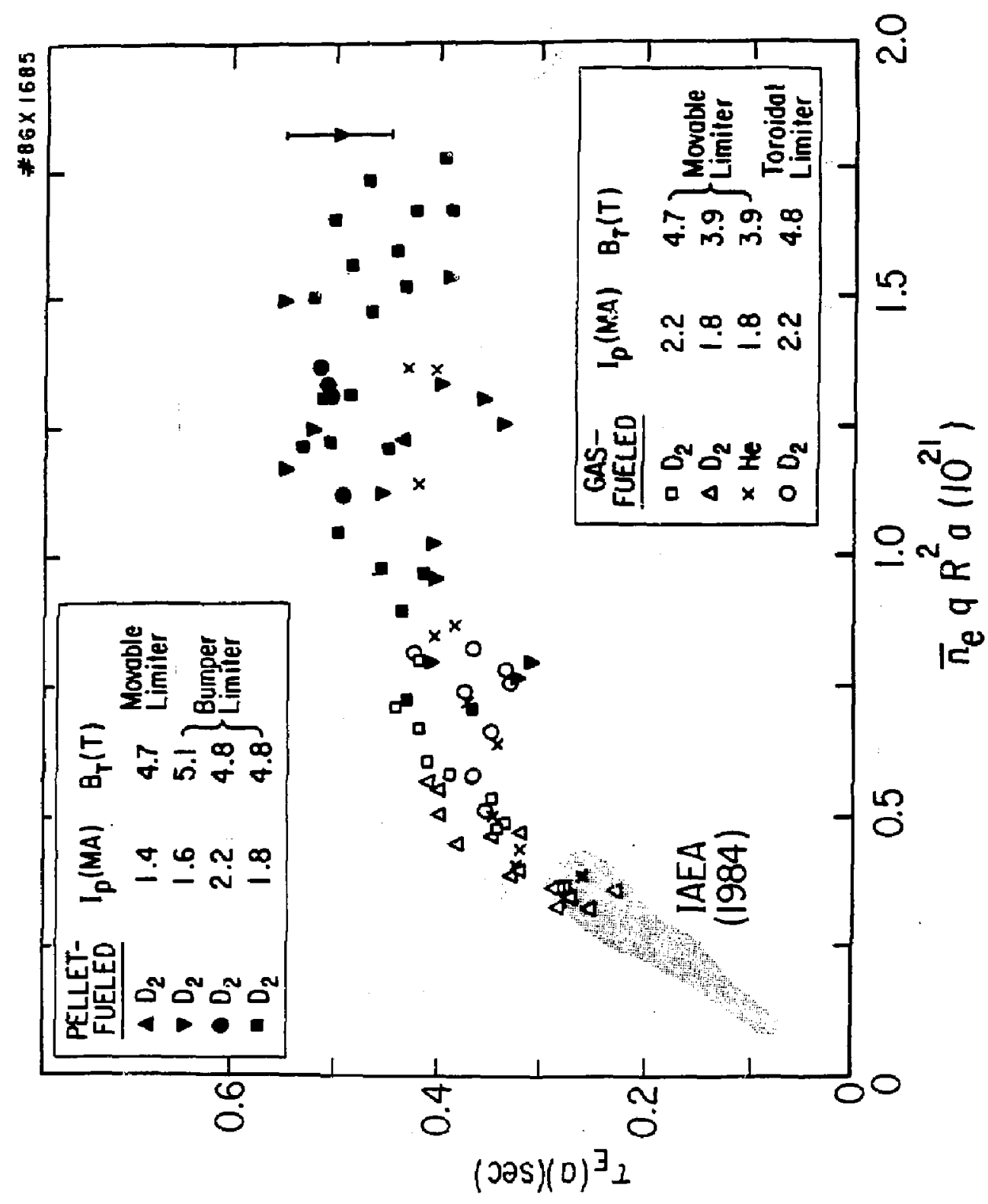

Fig. 1 


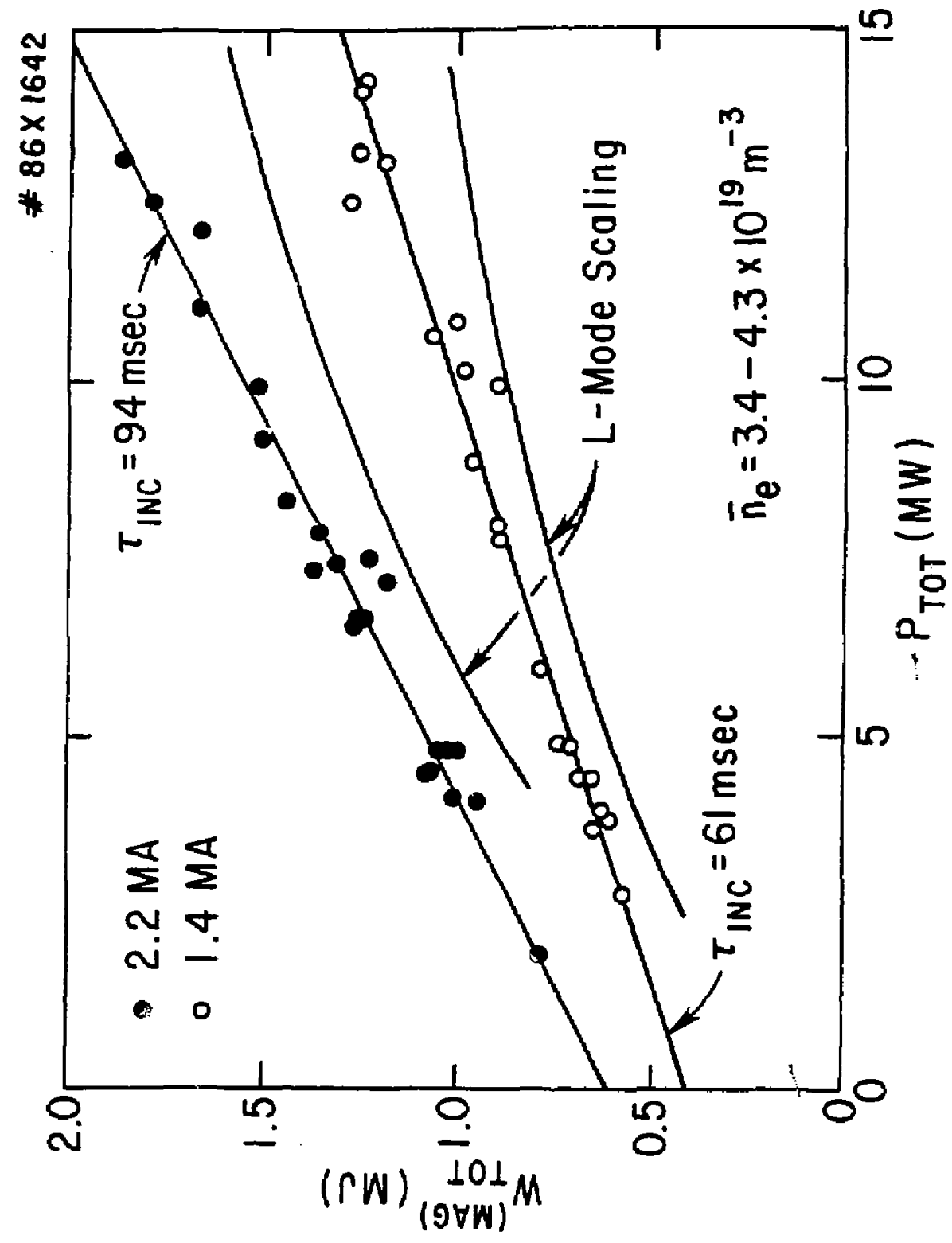

Fig. 2 


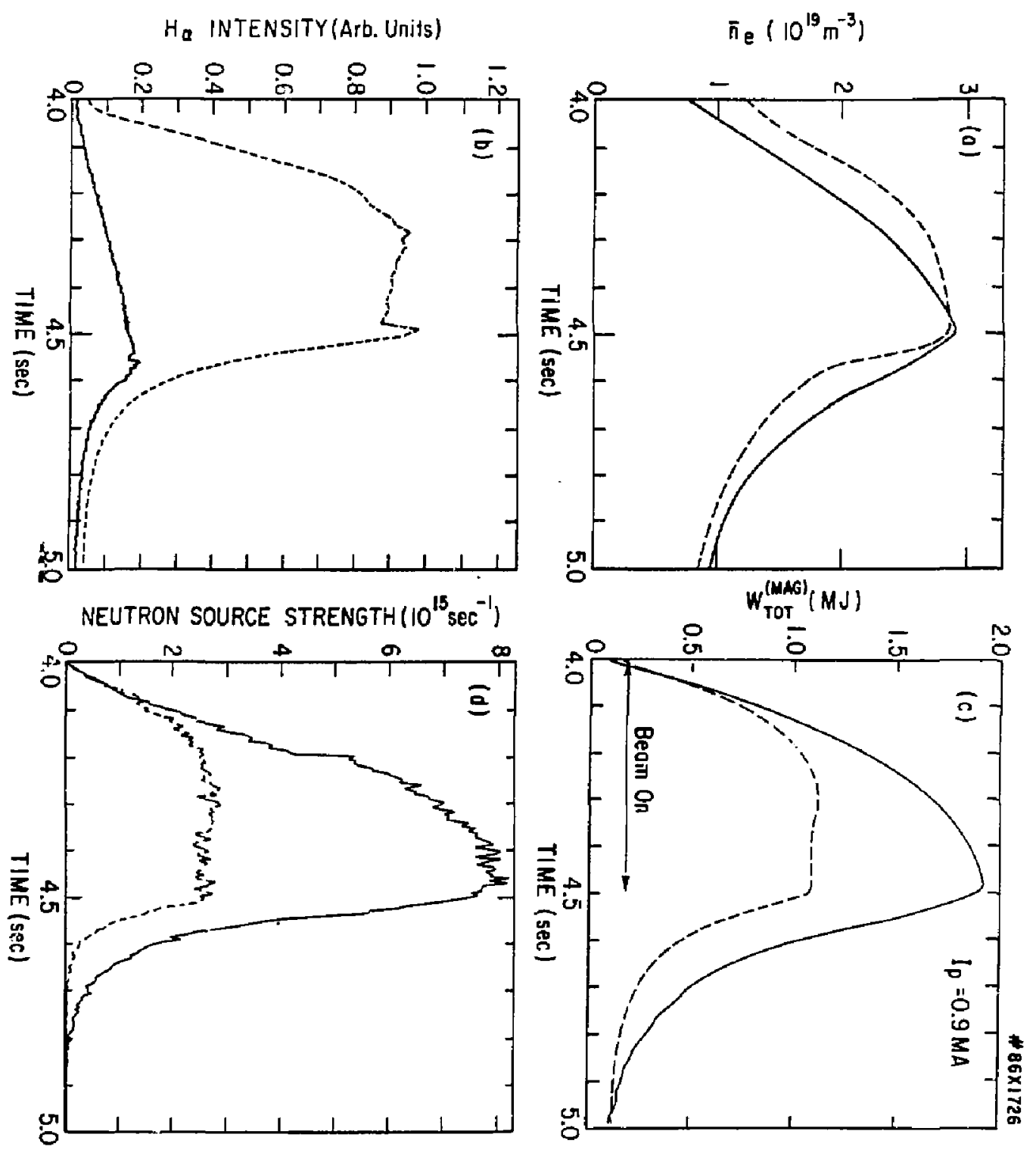



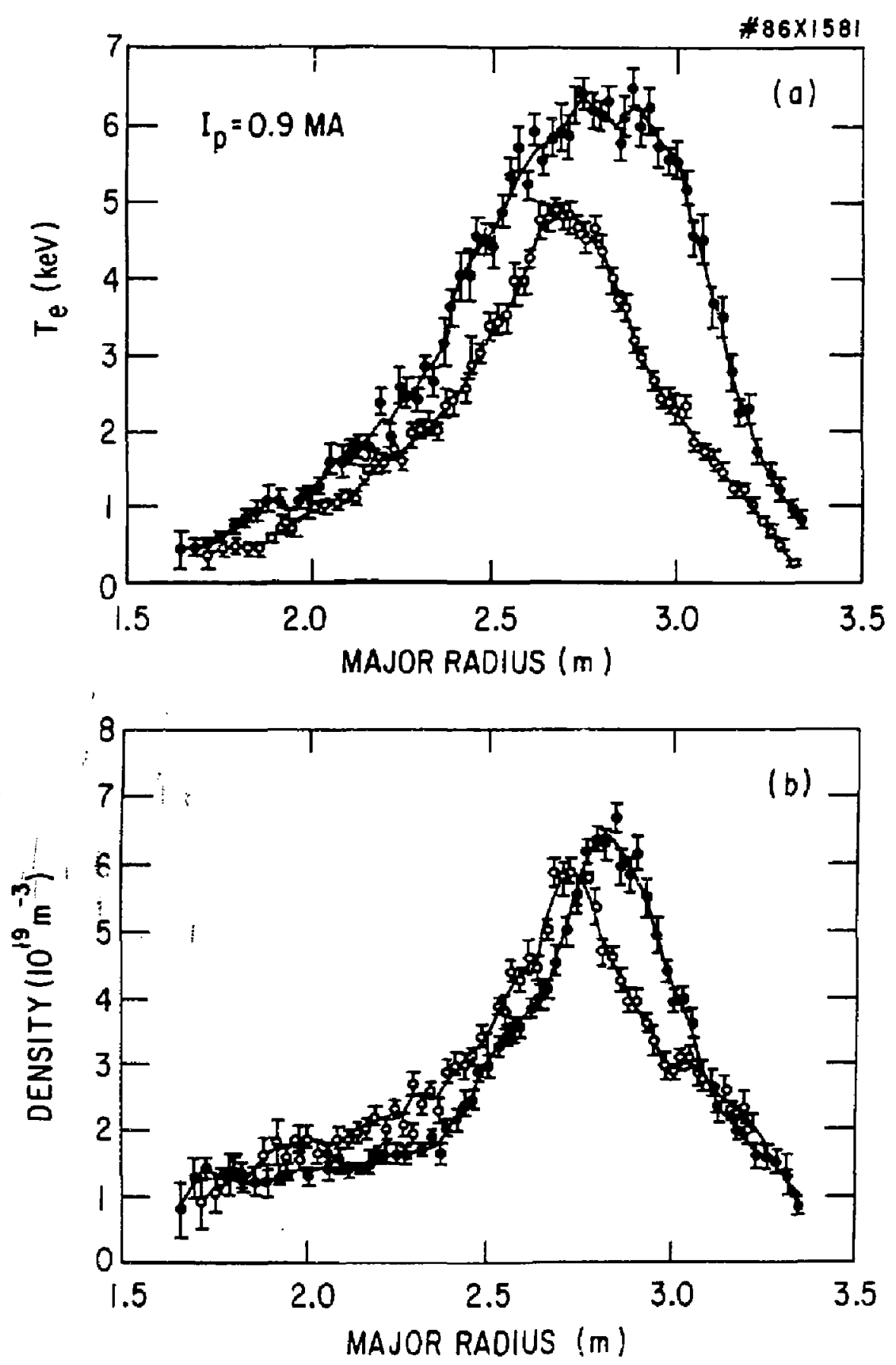

Fig. 4 


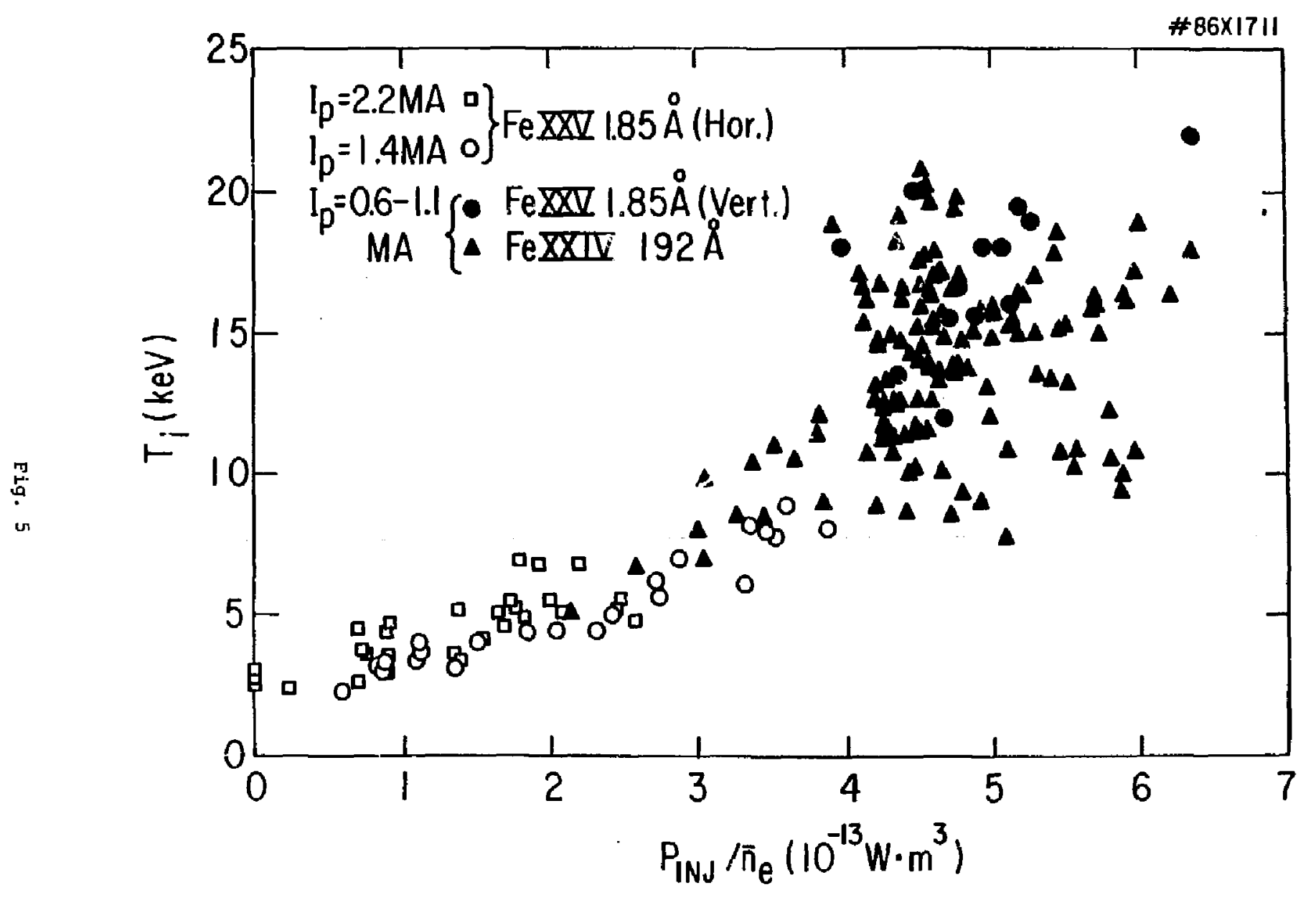




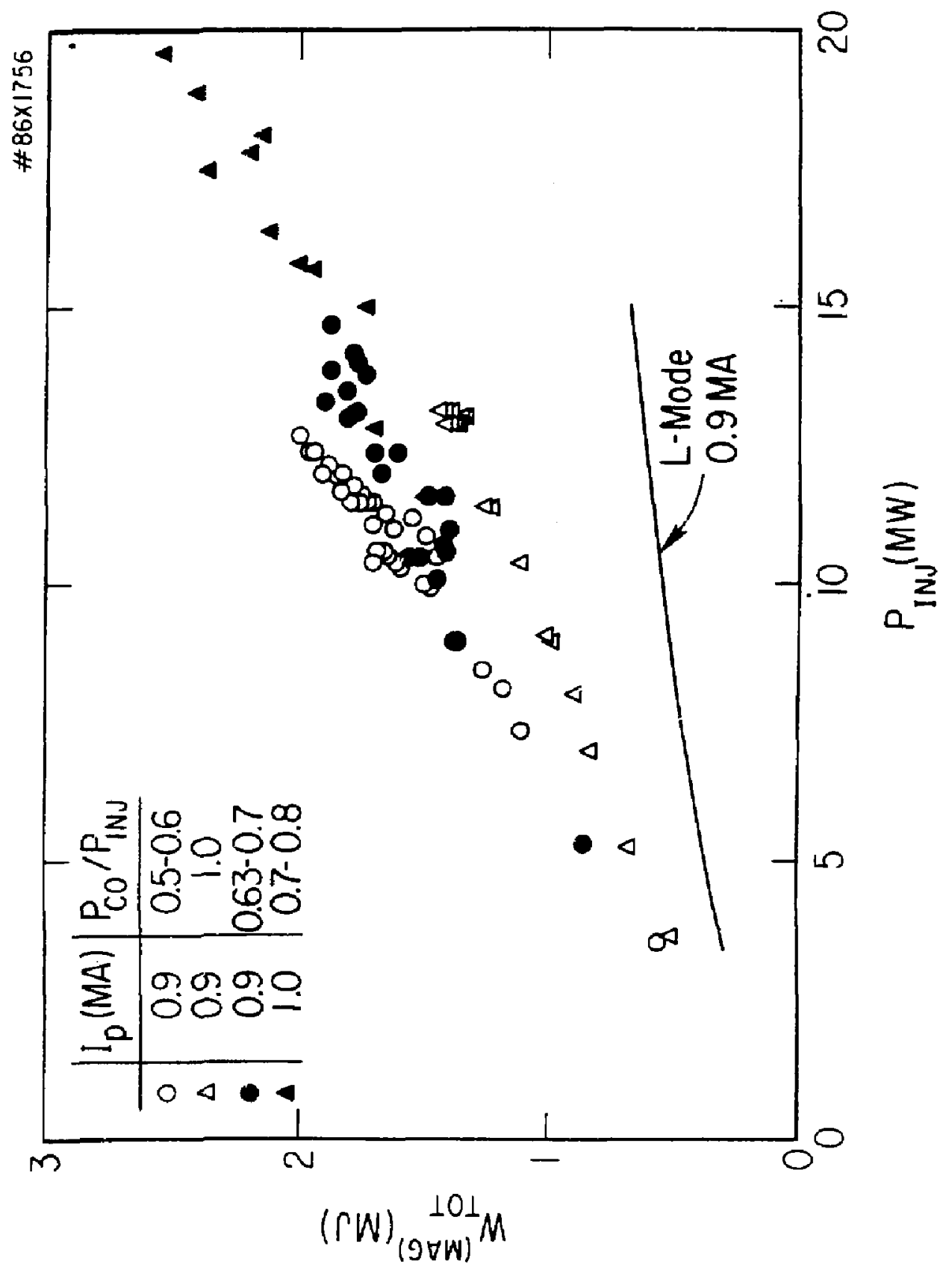

Fig. 6 


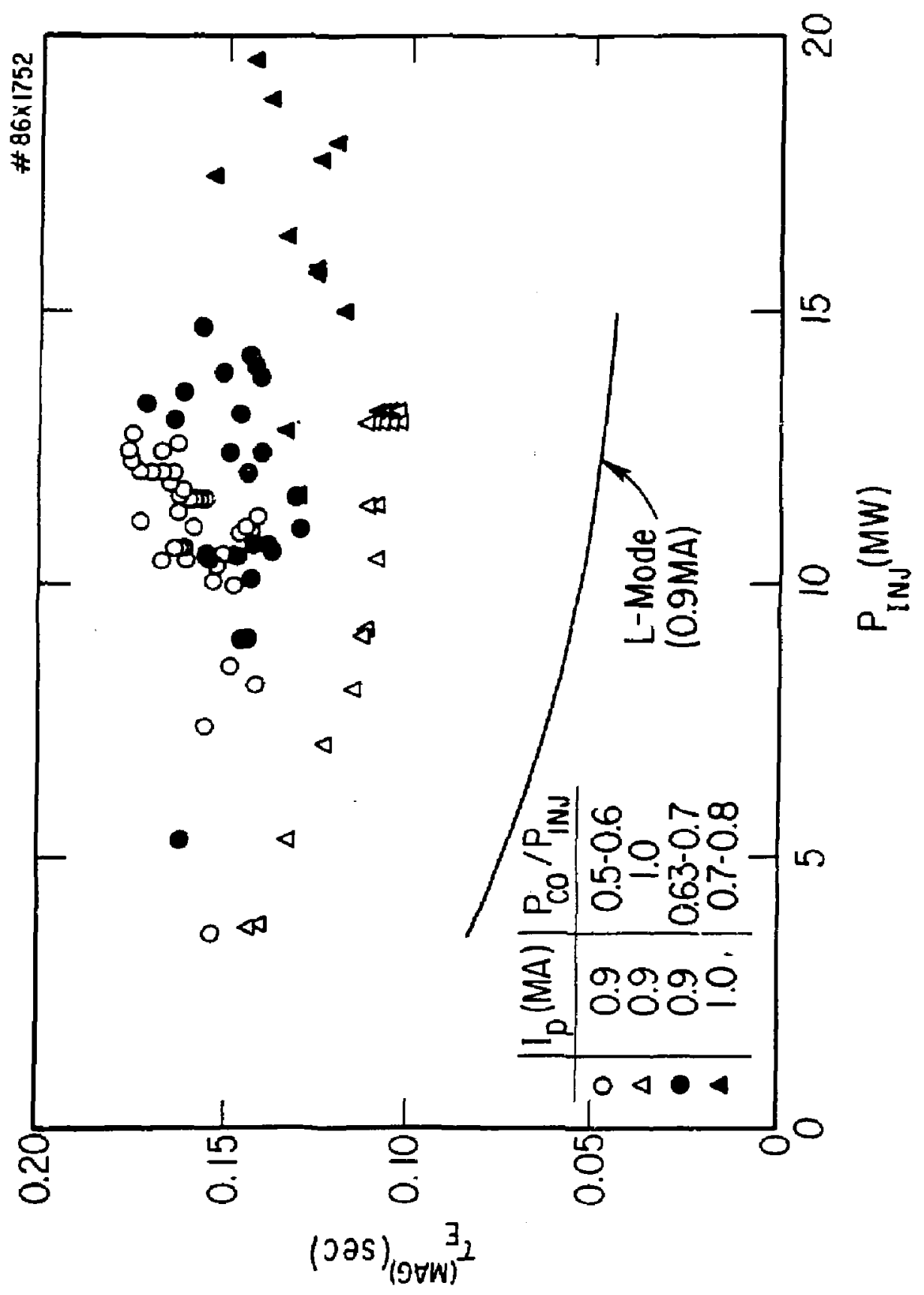

Fig. 7 


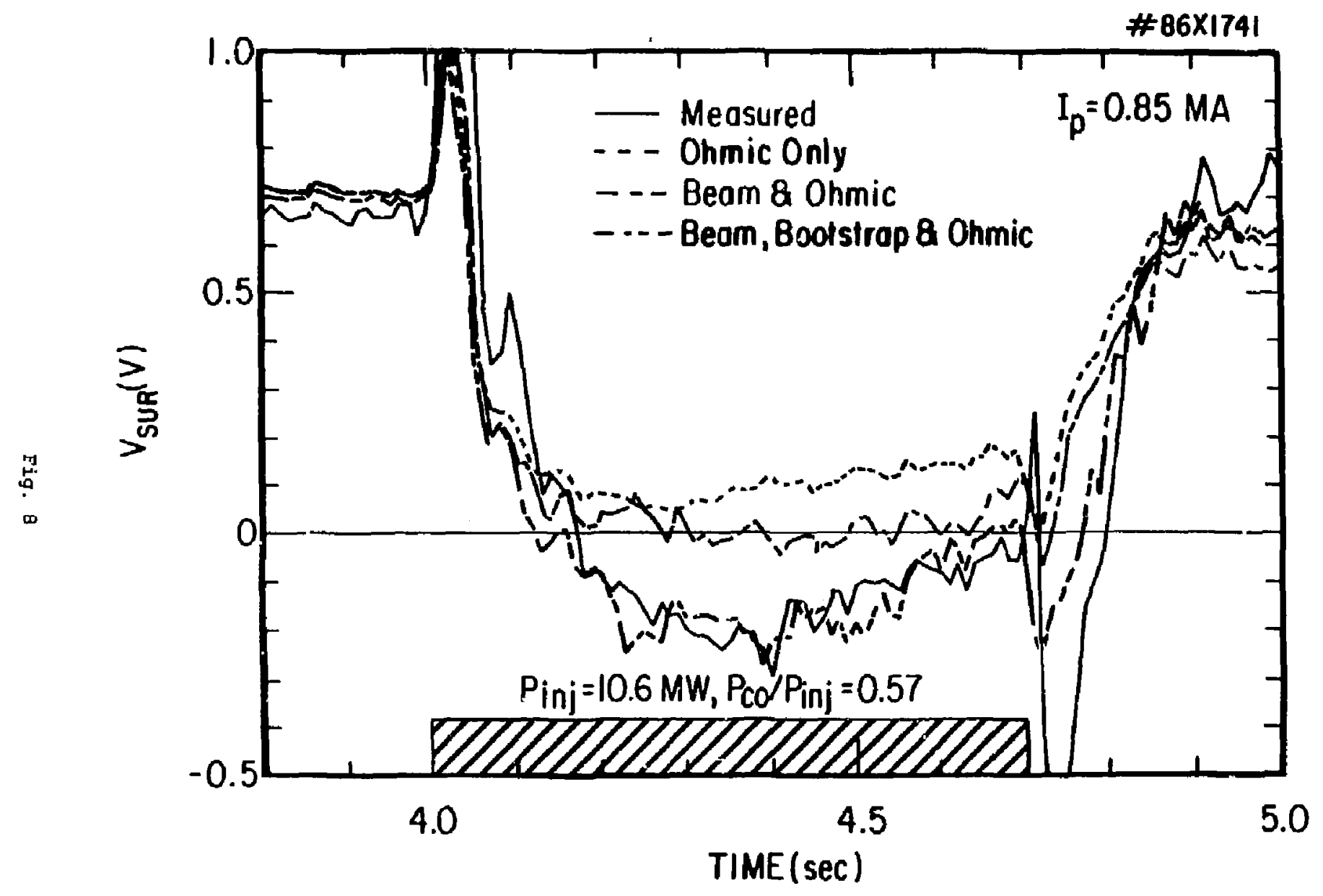


Dr. Frank J. Pooloni, Univ of Wollongong, AUSTRALIA

Prot. M.H. Groman, Univ Sydney, hustRabia

Plasma Research Lab., Australlan Nat. Univ.., AUSTRALIA

Prot. I.R. Janes, Fllinders Univ., NUSTRRLIA

Prot, F. Cap, Inst Theo Phys, AUSTRIA

Prot. M. Halndler, Institut tur Theoretische Physik, AUSTRIA

M. Goossens, Astronomisch Instituut, BELGIUM

Ecole Royala milltalra, Lab de Phys Plasas, BELGIUm

Com, of European, Og XII Fusion Prog, BELGIum

Prot. R. Boucique, Laboratorlum voor Natuurkunde, BELGIUM

Dr. P.H. Sakenaka, Unlv Estodual, BRAZIL

Instituto Ou Pesquisos Espaclasi-1 MPE, BRAZIL

LIbrary. Atomle Enorgy of Canada LIalted, CANADA

Dr. M.P. Eachynskl, MPB Tochnoloujles, Ine., CNAOA

Dr. H.M. Skarsgard, Unlv of Saskatchemen, CANADA

Dr. H. Barnard, Univarsity of BritIsh Columbla, CNANDA

Prof. J. Teichmann, Univ. at Montreal, CANADA

Prof. S.R. Sroenlvasan, University of Caigary, CAMADA

Prot. Tudor W. Johnston, INAS-Energle, CNNOA

Or. C.R. James, UnIV. of Alberta, CANNOA

Dr. Puter Lukac, Komensketho UnIv, CZECHOSLOVMIA

Tha LIbrarlan, Culhon Laboratory, ENGLNO

Mrs. S.A. Hutehinson, JeT Library, ENGLAD

C. Houtter, Lob. de Physlate des Milleox lonises, fRAMCE

J, Fadot, CEN/CADARAOHE - Eat 506, FRMUCE

Dr. Tom Aual, Academy Blbllographle, hONG KONG

Preprint LIbrary, Cont Ros inst Phys, HUMGNRY

Dr. 9. Oasgupra, Sahe inst, iNolA

Dr. R.K. Chhajlanl, Vikram Univ. INDIA

Dr. P. Kow, Institute for Plasna Research, INOIA

Dr. Phllilp Rosertad, I srael Inst Tech, ISRAEL

Prof. S. Cuperman, Tol Aulv University, ISRAEL

Liorarlon, Int'l ctr theo Phys, ITALy

Prot. G. Rostogni, Univ DI Padova, ITALY

MIss Clelía De Palo, Assol EURATOL-ENEA, ITALY

BIbllotece, del GNR EUPATOH, ITAY

Or. H. Yomato, Toshlbe Res 8 Oev, JAPN

Prat. I. Kawakam1, Atomle Engrgy Ras. Institute, JAPAN

Prot. Kyojl Mishikawa, Unir of Hiroshlmo, JAPAN

Diroc. Dept. Lg. Tokamak Rus. JAERI, JAPAN

Prof. Satoshl Itoh, Kyushu UnIversity, JNPN

Research Into Conter, Nagoya UnIversity, JAPAN

Prot. S. Tanako, Kyoto Univarsity, JAPAN

LI Drary, Kyoto Unlversity. JAPAH

Prot. Nobuyuxl inowe, Universlty of Tokyo, JAPNA

S. MORJ, JAERI, JAPAN

M.H. KIn, Kores Advanced Enargy Resebreh Institute, KOREA

Prof. D.1. Chol, Adv. Inst Sel \& Tech, KOAEA

Prof. B.S. LIIN, Unlversity at walkato, NEW ZFALAMO

institute of Plasma PhyslCs, PEOPLE's REPU⿴LIC OF CHINA

Librarian, Institute of Phys., PEOPLE'S REPUaLIC OF CHIMA

LIbrary, Tsling Hud University, FEOPLE'S REPUBLIC OF CHINA
Z. LI, Southwest Inst. Physles, PECPLE'S RgPU⿴LIC OF CHINA Prof. J.A.C. Cabral, Inst 5uparlor Toch, PORTUGAL

Dr. Detaslan Potrus, AL I CUzA UnIvirstity, ROMANIA

Dr. Johan de Villiors, Plosme Physics, AEC, SO AFRICA

Prof. M.A. Hellberg, Unlversity of Natal, SO AFRICA

Fusion DIV, LIOrary, JEN, SPAIN

Dr. Lennart Stentlo, University of UMEA, SHEDEN

LIbrary, Royal Inst Toeh, SWEDEN

Prot. Hans Wlihwimson, Chalmars UnIy Tech, SHEDEN

Centro Phys des Plasnes, Ecolo Polytech Fod, SWITZERLAND

Gibilathedk, Fom-1ngt yoor Plasna-Fysico, THE NETHERiAHOS

Dr. D.0. Ryutov, Sibarlan Acad Scl, USSR

Dr. G.A. Ellseev, Kurchator Institute, USSR

Dr, $V, A$, blukhlkh, Inst Electramphyslical, LSSR

Or. Y.T. Tolok, Inst. Phys. Tech. USSR

Or. L.M. Kovrizhnykh, Institute Gen. Physlcs, USSR

Prof. T.J.M. Bayd, Unlv Colloge $N$ Wales, WALES

Nuclear Res. Establishment, Julich Ltd.., W. GERMANY

Blbllothek, inst. Fur Plasmaforschung, W. GERMANY

Ur. K, Schindiar, Ruhr Unlversitat. W. GERMAHY

ASDEX Reading Rn, IPP/Max-Planck-I nstitut tur

Plasiaphys IK, W. GERuNY

LIbrarlian, Mox-Planck Instltut, W. GERMANY

Prof. R.k. Jener, Inst Phys, YugosLavia 